\title{
KEPUASAN PENGUNJUNG TEMPAT WISATA PEMANDIAN HAIROS WATERPARK MEDAN
}

\author{
Dita Amanah dan Kustoro Budiarta \\ Universitas Negeri Medan \\ Dedy Ansari Harahap \\ Universitas Islam Sumatera Utara
}

\begin{abstract}
This article analyzes the satisfaction of visitors to the tourist attractions of Hairos Waterpark Medan. The sample in this study was 90 respondents with a purposive sampling as a sampling technique that is only addressed to respondents who have made visit to Hairos Waterpark. Data analysis technique used is a simple linear regression because it only analyzed service quality to the visitor satisfaction in Hairos Waterpark. The regression result was $Y=3.006+0.269 X+e$. The t test result was 3.452 and the coefficient of determination was 0.119 . These results indicate that service quality positively and significantly influence to the visitor satisfaction in Hairos Waterpark Medan. Therefore, Hairos Waterpark management really needs to consider the quality of service in influencing people to visit Hairos Waterpark and further affecting visitor's satisfaction. Limitations and suggestions are also discussed in this article.
\end{abstract}

\section{Keywords: Service Quality, Satisfaction, Waterpark, Simple Linear Regression}

\section{PENDAHULUAN}

Medan merupakan ibu kota dari provinsi Sumatera Utara. Medan merupakan pintu masuk ke Indonesia bagian barat, berbatasan dengan Malaysia yang dipisahkan dengan Selat Malaka. Medan dahulu dan sekarang adalah pusat industri dan perdagangan dengan pelayanan komunikasi yang cukup memadai ke seluruh wilayah Sumatera Utara. Sebagai pintu masuk ke Indonesia bagian barat, Bandar Udara Internasional memiliki penerbangan langsung keluar negeri dan penerbangan dalam negeri (penerbangan domestik).

Objek wisata yang dimiliki daerah Kota Medan terbentuk dari kondisi geografis, sejarah, dan budaya yang dimiliki daerah Kota Medan terbentuk dari kondisi geografis, sejarah, dan budaya yang dimiliki daerah Kota Medan. Potensi wisata yang berasal dari kondisi geografis meliputi obyek wisata alam dan obyek wisata buatan. Objek wisata alam adalah tempat wisata yang bersifat secara alami, bisa saja terbentuk karena letak geografisnya. Sementara objek wisata buataan adalah tempat wisata yang dibuat oleh manusia.

Potensi wisata dari objek wisata sejarah dan budaya (human resources), yang dikenal di kota Medan yaitu Museum Sumatera Utara, Istana Maimun, dan masih ada beberapa lagi jenis objek wisata budaya yang dapat ditemui di Kota Medan. Wisata pemandian termasuk salah satu tempat wisata yang saat ini lagi tren dibangun oleh pengusaha di kota Medan. Masyarakat yang butuh tempat hiburan dan sekaligus wisata pemandian yang dekat dengan pemukiman masyarakat atau masih dalam kisaran dalam kota, menjadi 
alasan utama pemilihan lokasi pemandian berdasarkan keinginan masyarakat.

Salah satu tempat wisata pemandian yang saat ini sering dikunjungi di kota Medan adalah Hairos Waterpark. Hairos Waterpark merupakan tempat wisata pemandian keluarga yang terbesar dan terlengkap di Sumatera Utara yang berlokasi di Jalan Jamin Ginting km. 14 Medan. Tempat ini sangat cocok untuk dikunjungi saat liburan apalagi waktu liburan yang dimiliki sangat sigkat. Tidak perlu ke luar kota, cukup di dalam kota kita sudah menemukan objek wisata ini. Berbagai fasilitas hiburan tersedia seperti bom bom car, happy dragon, mini flight, kuda pusing, video game. Café pun disediakan oleh pengelola untuk bersantai dengan keluarga, teman ataupun kerabat. Selain itu juga terdapat kebun binatang, perahu sampan, motor ATV, kincir angin dan waterpark tentunya sebagai wisata utama yang ditawarkan pengelola.

Objek wisata menjadi penting bagi pembangunan dan perkembangan suatu daerah karena beberapa faktor. Pertama adalah keberadaan masyarakat. Wisata merupakan sektor jasa yang sejalan dengan kehidupan masyarakat modern. Semakin tinggi pendidikan dan pendapatan seseorang, maka akan semakin besar kebutuhaan meraka akan wisata. Kedua, wisata mempunyai keterkaitan yang sangat erat dengan berbagai bidang lain. Oleh karena itu pariwisata akan berkembang seiring dengan perkembangan bidang lainnya seperti telekomunikasi, lingkungan hidup, transportasi, sumber daya manusia dan sabagainya. Ketiga, daya tarik suatu objek wisata tergantung dari kekuatan daya saing yang dimiliki pengelola yaitu dengan manajemen yang baik terhadap objek wisatanya (Badan Pusat Statistik, 2016).

Penilaian terhadap suatu objek wisata memiliki peran yang dapat menentukan perkembangan dan kemajuan tempat wisata tersebut yang mencakup berbagai faktor seperti salah satunya adalah kualitas pelayanan. Kualitas pelayanan yang dirasakan baik oleh pengunjung suatu objek wisata akan dapat menciptakan kepuasan bagi mereka. Sebaliknya, apabila tempat wisata memberikan pelayanan yang buruk maka pengunjung tidak akan mau lagi berkunjung ke tempat tersebut. Pelayanan yang dirasakan dan pelayanan yang diharapkan harus diperhatikan pengelola. Pelayanan yang dirasakan harus lebih tinggi daripada pelayanan yang diharapkan pengunjung. Oleh karena itu pengelola perlu memperhatikan dimensi kualitas pelayanan sehingga pengunjung merasa puas dan memenuhi harapan mereka serta diharapkan akan melakukan kunjungan kembali ke Hairos Waterpark Medan. Sikap dan pelayanan merupakan hal yang terpenting dan sangat menentukan kualitas pelayanan tempat wisata.

pengumuman right issue yang mengakibatkan terjadi perdagangan saham.

\section{KAJIAN PUSTAKA \\ Kepuasan Pelanggan \\ Pengertian Kepuasan Pelanggan}

Kepuasan pelanggan adalah perasaan senang atau kecewa yang muncul setelah membandingkan kinerja (hasil) produk yang dipikirkan 
terhadap kinerja (atau hasil) yang diharapkan (Kotler \& Armstrong, 2014). Tanggapan konsumen terhadap evaluasi perbedaan persepsi antara harapan sebelumnya dan kinerja aktual produk atau layanan sebagaimana dirasakan setelah dikonsumsi adalah maksud dari kepuasan pelanggan (Tse \& Wilton, 1988). Jadi konsumen melakukan evaluasi secara keseluruhan dari sebelum melakukan pembelian sampai pasca pembelian dalam mempertimbangkan kepuasan yang diterimanya (Fornell, 1992). Respon kognitif atau afektif yang dirasakan konsumen terhadap objek tertentu juga disebut kepuasan pelanggan (Giese \& Cote, 2002).

Dari beberapa pendapat sebelumya, dapat dikatakan bahwa kepuasan pelanggan merupakan suatu pemenuhan harapan. Pelanggan dapat dikatakan puas dengan produk maupun pelayanan yang diberikan apabila harapan pelanggan akan produk/pelayanan yang diberikan tersebut telah sesuai bahkan melebihi harapan mereka. Konsumen yang merasa puas adalah konsumen yang menerima nilai tambah yang lebih dari perusahaan. Memuaskan konsumen tidak hanya berarti memberikan tambahan produk atau jasa, pelayanan ataupun sistem. Kepuasan pelanggan merupakan suatu hal yang sangat berharga demi mempertahankan keberadaan pelanggan tersebut untuk tetap berjalannya bisnis atau usaha. Dalam industri jasa, kepuasan pelanggan diukur dengan tingkat kepuasan pelanggan berdasarkan keseluruhan pengalaman dengan perusahaan. Dengan kata lain, kepuasan pengunjung Hairos Waterpark dapat diukur dengan tingkatannya berdasarkan keseluruhan pengalaman yang dirasakan para pengunjung selama menikmati hiburan dan wisata pemandian.

\section{Pengukuran Kepuasan Pelanggan}

Perusahaan perlu mengukur kepuasan pelanggan guna melihat umpan balik maupun masukan yang dapat diambil oleh perusahaan untuk keperluan pengembangan dan implementasi strategi peningkatan kepuasan pelanggan. Kotler \& Keller (2016a) mengemukakan bahwa terdapat empat metode untuk mengukur kepuasan pelanggan, yaitu:

1. Sistem keluhan dan saran. Setiap perusahaan yang berpusat pada pelanggan (customer centered) perlu memberikan kesempatan bagi pelanggannya untuk menyampaikan saran, pendapat, dan keluhan mereka. Banyak restoran dan hotel yang memberikan formulir bagi tamu untuk mengetahui kesukaan dan keluhan mereka. Alur informasi ini memberikan banyak gagasan baik dan perusahaan dapat bergerak cepat untuk menyelesaikan masalah.

2. Survei kepuasan pelanggan. Perusahaan tidak dapat beranggapan bahwa sistem keluhan dan saran dapat menggambarkan secara lengkap kepuasan dan kekecewaan pelanggan. Perusahaan yang responsif mengukur kepuasan pelanggan dengan mengadakan survei berkala. Mereka mengirimkan daftar pertanyaan atau menelpon suatu kelompok acak dari pembeli mereka untuk mengetahui perasaan mereka terhadap berbagai aspek 


$$
\begin{array}{lrr}
\text { kinerja } & \text { perusahaan. } & \text { Perusahaan } \\
\text { juga } & \text { menanyakan } & \text { pendapat } \\
\text { pembeli mengenai } & \text { kinerja } \\
\text { perusahaan pesaing. } &
\end{array}
$$

3. Ghost Shopping (pembeli bayangan). Metoda ini dilaksanakan dengan cara mempekerjakan beberapa orang (ghost shopper) untuk berperan sebagai pelanggan atau pembeli potensial produk perusahaan pesaing untuk melaporkan titiktitik kuat maupun titik-titik lemah yang mereka alami waktu membeli produk perusahaan maupun produk pesaing. Ghost shopper juga dapat mengamati cara penanganan setiap keluhan.

4. Lost customer analysis (analisis pelanggan yang beralih). Perusahaan sebaiknya menghubungi para pelanggan yang telah berhenti membeli atau yang telah berpindah pemasok agar dapat memahami mengapa hal ini terjadi dan supaya dapat mengambil kebijakasanaan perbaikan atau penyempurnaan selanjutnya.

Kepuasan pelanggan merupakan fungsi dari kualitas pelayanan dikurangi harapan pelanggan dengan kata lain pengukuran kepuasan konsumen dirumuskan sebagai berikut (Kotler \& Armstrong, 2016):

\section{Service quality Less Than} Expectation

Bila ini terjadi, dapat dikatakan bahwa pelayanan yang diberikan perusahaan buruk. Selain tidak memuaskan juga tidak sesuai dengan harapan pelanggan. Jika kualitas pelayanan yang diberikan perusahaan lebih kecil dari harapan pelanggan, maka akan mengakibatkan ketidakpuasan terhadap pelanggan.

2. Service quality = Expectation Bila ini terjadi dapat dikatakan bahwa pelayanan yang diberikan tidak ada keistimewaan. Jika nilai kualitas pelayanan yang diberikan perusahaan samdengan harapan pelanggan, maka muncul kepuasan yang biasa diinginkan pelanggan.

3. Service quality More Than Expectation

Bila ini terjadi dapat dikatakan bahwa pelanggan merasakan pelayanan yang diberikan oleh perusahaan tidak hanya sesuai dengan kebutuhan, namun sekaligus memuaskan dan menyenangkan. Jika kualitas pelayanan lebih besar dari harapan yang diinginkan pelanggan, maka akan membuat kepuasan pelanggan sangat luar biasa. Pelayanan ketiga ini disebut pelayanan prima (excellent service) yang selalu diharapkan oleh pelanggan.

\section{Kualitas Pelayanan}

Kualitas pelayanan pada dasarnya merupakan suatu konsep yang memberikan persepsi secara konkrit mengenai kualitas suatu layanan. Konsep kualitas pelayanan ini merupakan suatu revolusi secara menyeluruh, permanen dalam mengubah cara pandang manusia dalam menjalankan atau mengupayakan usaha-usahanya yang berkaitan dengan proses dinamis, berlangsung, terus menerus di dalam memenuhi harapan, keinginan dan kebutuhan.

Kualitas pelayanan adalah suatu persepsi tentang revolusi kualitas secara menyeluruh yang terpikirkan dan menjadi suatu gagasan yang harus 
dirumuskan (formulasi) agar penerapannya (implementasi) dapat diuji kembali (evaluasi), untuk menjadi suatu proses yang dinamis, berlangsung, terus menerus dalam memenuhi kepuasan pelanggan (Stemvelt, 2004). Konsep kualitas pelayanan pada dasarnya adalah suatu standar kualitas yang harus dipahami di dalam memberikan pelayanan yang sebenarnya tentang pemasaran dengan kualitas layanan. Hal tersebut bukan hanya bersifat cerita atau sesuatu yang mengada-ada, tetapi harus disesuaikan dengan suatu standar yang layak, seperti standar ISO (International Standardization Organization), sehingga dianggap sebagai suatu kondisi yang sehat untuk tujuan atau pemakaian, memiliki keselarasan dengan spesifikasi, kebebasan dengan segala kekurangannya, membentuk kepuasan pelanggan, memiliki kredibilitas yang tinggi dan merupakan kebanggaan.

(Yeong, Chang, \& Loh, 1997) memberikan suatu pengertian bahwa konsep kualitas layanan adalah suatu kecocokan untuk penggunaan (fitness for yours) yang bertujuan untuk menemukan suatu pemikiran yang jelas dari proses pemikiran yang melahirkan adanya suatu pemahaman yang tidak sulit untuk dipahami, karena tujuannya jelas dan prosesnya merupakan continue quality improvement (proses yang berkelanjutan).

Tinjauan mengenai konsep kualitas layanan sangat ditentukan oleh berapa besar kesenjangan (gap) antara persepsi pelanggan atas kenyataan pelayanan yang diterima, dibandingkan dengan harapan pelanggan atas pelayanan yang harus diterima. Menurut Parasuraman
(2002) bahwa konsep kualitas layanan yang diharapkan dan dirasakan ditentukan oleh kualitas layanan. Kualitas layanan tersebut terdiri dari daya tanggap, jaminan, bukti fisik, empati dan kehandalan. Selain itu, pelayanan yang diharapkan sangat dipengaruhi oleh berbagai persepsi komunikasi dari mulut ke mulut, kebutuhan pribadi, pengalaman masa lalu dan komunikasi eksternal, persepsi inilah yang memengaruhi pelayanan yang diharapkan (Ep = Expectation) dan pelayanan yang dirasakan (Pp $=$ Perception) yang membentuk adanya konsep kualitas layanan

\section{Mengelola Kualitas Pelayanan}

Suatu cara perusahaan untuk dapat unggul bersaing adalah memberikan pelayanan dengan kualitas yang lebih tinggi dari pesaingnya secara konsisten. Harapan konsumen dibentuk oleh pengalaman masa lalunya, pembicaraan dari mulut ke mulut serta promosi yang dilakukan oleh perusahaan pelayanan, kemudian dibandingkannya. Daniel \& Berinyuy (2010) membentuk model kualitas pelayanan yang menyoroti syarat-syarat utama untuk memberikan kualitas pelayanan yang tinggi. Model itu mengidentifikasi lima kesenjangan yang mengakibatkan kegagalan penyampaian pelayanan :

1. Kesenjangan antara harapan konsumen dan persepsi manajemen.

Manajemen tidak selalu memahami secara tepat apa yang diinginkan konsumen.

2. Kesenjangan atara persepsi manajemen dan spesifikasi kualitas pelayanan. 
Manajemen mungkin memahami secara tepat keinginan konsumen tetapi tidak menetapkan suatu set standar kinerja spesifik.

3. Kesenjangan antara spesifikasi kualitas pelayanan dan penyampaian pelayanan.

Para personil mungkin kurang teliti atau tidak mampu atau tidak mau memenuhi standar atau mereka dihadapkan pada standar yang berlawanan, seperti menyediakan waktu untuk mendengarkan para konsumen dan melayani mereka dengan cepat.

4. Kesenjangan antara penyampaian pelayanan dan komunikasi eksternal.

Harapan konsumen dipengaruhi oleh pernyataan yang dibuat oleh wakil perusahaan dan iklan perusahaan.

5. Kesenjangan antara pelayanan yang dialami dan pelayanan yang diharapkan.

Kesenjangan ini terjadi bila konsumen memiliki persepsi yang keliru tentang kualitas pelayanan tersebut.

\section{METODE PENELITIAN}

Penelitian ini dilakukan di Hairos Waterpark Medan. Sampel berjumlah sembilan puluh orang yaitu responden yang pernah melakukan kunjungan ke Hairos Waterpark dengan sampel bertujuan (purposive sampling) sebagai teknik sampel. Metode analisis regresi linier sederhana digunakan untuk menganalisis data penelitian. Selain itu uji t digunakan untuk mengetahui pengaruh antara variabel independen (kualitas pelayanan) terhadap variabel dependen (kepuasan pelanggan). Uji koefisien determinasi dilakukan untuk menjelaskan prosentase variabel dependen yang ditentukan oleh variabel independen.

\section{HASIL PENELITIAN DAN PEMBAHASAN \\ Hasil Penelitian \\ Penelitian ini memperoleh hasil} seperti yang diuraikan sebagai berikut:

1. Hasil regresi adalah $\mathrm{Y}=3,006+$ $0,269 \mathrm{X}+\mathrm{e}$, menjelaskan bahwa jika kualitas pelayanan (X) tidak ada atau bernilai 0 , maka kepuasan pelanggan (Y) bernilai 3,006. Nilai $0,269 \mathrm{X}$ menjelaskan bahwa jika terjadi kenaikan satu unit kualitas pelayanan, maka akan mempengaruhi kepuasan pelanggan sebesar 0,269 (Tabel 1).

2. Hasil uji $t$ adalah sebesar 3,452 , menunjukkan bahwa kepuasan pelanggan dipengaruhi oleh kualitas pelayanan secara positif dan signifikan (Tabel 1).

Tabel 1. Hasil Uji t dan Analisis Regresi

Coefficients $^{\mathrm{a}}$

\begin{tabular}{|c|c|c|c|c|c|c|c|}
\hline \multirow[b]{2}{*}{ Model } & \multicolumn{2}{|c|}{$\begin{array}{c}\text { Unstandardized } \\
\text { Coefficients }\end{array}$} & \multirow{2}{*}{\begin{tabular}{|c|}
$\begin{array}{c}\text { Standardized } \\
\text { Coefficients }\end{array}$ \\
Beta \\
\end{tabular}} & \multirow[b]{2}{*}{$\mathrm{t}$} & \multirow[b]{2}{*}{ Sig. } & \multicolumn{2}{|c|}{$\begin{array}{c}\text { Collinearity } \\
\text { Statistics }\end{array}$} \\
\hline & B & Std. Error & & & & Tolerance & VIF \\
\hline (Constant) & 3.006 & .256 & & 11.748 & .000 & & \\
\hline $\begin{array}{l}\text { kualitas } \\
\text { pelayanan }\end{array}$ & .269 & .078 & .345 & 3.452 & .001 & 1.000 & 1.000 \\
\hline
\end{tabular}

a. Dependent Variable: kepuasan

3. Hasil uji koefisien determinasi kepuasan pelanggan pada Hairos (R2) adalah 0.119 , berarti $11,9 \%$ Waterpark Medan dijelaskan oleh 
kualitas pelayanan. Selebihnya $88,1 \%$ dijelaskan oleh faktor lain di luar penelitian ini (Tabel 2).

Tabel 2. Hasil Uji R2 Model Summary

\begin{tabular}{|l|c|r|r|c|}
\hline Model & $\mathrm{R}$ & $\begin{array}{c}\mathrm{R} \\
\text { Square }\end{array}$ & $\begin{array}{c}\text { Adjusted } \\
\text { R Square }\end{array}$ & $\begin{array}{c}\text { Std. Error } \\
\text { of the } \\
\text { Estimate }\end{array}$ \\
\hline 1 & $.345^{\mathrm{a}}$ & .119 & .109 & .63130 \\
\hline
\end{tabular}

a. Predictors: (Constant), kualitas pelayanan

b. Dependent Variable: kepuasan

\section{Pembahasan Penelitian}

Penelitian ini menemukan bahwa kualitas pelayanan memiliki pengaruh terhadap kepuasan pelanggan. Hasil penelitian ini sejalan dengan Jin, Lee, \& Lee (2015) yang menemukan bahwa persepsi pelanggan mengenai kualitas (produk dan pelayanan) yang dirasakan mempengaruhi nilai, citra, kepuasan pelanggan dan niat untuk mengunjungi pertama kali dan berkunjung kembali ke tempat pemandian di bagian selatan Korea Selatan. Pengaruh kualitas terhadap kepuasan pelanggan dan citra tempat pemandian secara signifikan berbeda antara pelanggan yang baru pertama kali berkunjung dengan kunjungan ulang. Harmen, Agustini, Harahap, \& Amanah (2017) juga mendukung hasil penelitian ini. Mereka menyatakan bahwa kualitas pelayanan memiliki pengaruh positif dan signifikan terhadap kepuasan pengunjung pada Pantai Cermin, walaupun nilainya lebih kecil dibanding harga dan lokasi pada penelitian tersebut. Keselamatan dan keamanan menjadi faktor penting bagi pengunjung yang mempengaruhi kepuasan mereka di tempat pemandian di Korea (Kim, 2011). Pengunjung tidak begitu mempertimbangkan harga tiket masuk ke tempat pemandian asalkan mereka mendapatkan keselamatan dan keamanan ketika berada di tempat pemandian tersebut. Berdasarkan $\mathrm{Wu}$, Li, \& Li (2018), terdapat 4 (empat) dimensi primer dan 11 sub dimensi pengalaman kualitas yang dirasakan pengunjung pada taman bermain Janfusan Fancyworld, Taiwan. Kualitas (produk dan pelayanan) menciptakan kepuasan bagi pengunjung dan selanjutnya memotivasi mereka untuk melakukan kunjungan ulang ke taman bermain Janfusan Fancyworld, Taiwan.

Kualitas pelayanan merupakan faktor terpenting pada industri perhotelan. Pelayanan sangat diperhatikan dan sangat mempengaruhi kepuasan pengunjung hotel. P.Srinivas Rao (2013) menemukan bahwa pelanggan merasa puas dengan kualitas pelayanan staf front office di Hotel May Fair, Bhubaneswaice. Dimensi empati merupakan yang terlemah dan perlu dilakukan pelatihan bagi staf untuk meningkatkan kinerja mereka dalam melayani tamu hotel. Sementara dimensi tangible merupakan yang terkuat dalam penelitian ini sehingga perlu dipertahankan dan ditingkatkan keberadaannya. Kualitas pelayanan di sektor perbankan adalah kriteria dan aset yang paling penting untuk mengevaluasi dan memuaskan pelanggan sehingga dapat meningkatkan loyalitas pelanggan dan rata-rata tingkat retensi pelanggan. Persaingan pada dunia perbankan di India yang pada umumnya menawarkan produk yang sejenis, mengharuskan bank untuk mempertimbangkan kualitas pelayanan sebagai unsur pembeda yang krusial dibanding bank pesaing 
lainnya agar dapat memberikan pelayanan yang terbaik kepada nasabah. Kehandalan, jaminan dan empati memainkan peran yang vital di dalam organisasi yang menawarkan jasa seperti bank (Selvakumar, 2015).

\section{PENUTUP}

\section{Implikasi Penelitian}

Penelitian ini diharapkan menjadi masukan bagi pengelola Hairos Waterpark Medan dengan memberikan perhatian pada kualitas pelayanan sebagai salah satu faktor penentu yang dapat mempengaruhi kepuasan pelanggan.

\section{Batasan Penelitian}

1. Penelitian ini hanya membahas mengenai satu variabel yaitu kualitas pelayanan dalam mengidentifikasi kepuasan pelanggan.

2. Jumlah responden dan metode penelitian dianggap kurang mencukupi dan kurang memadai.

\section{Rekomendasi}

Peneliti lain diharapkan melakukan penelitian lanjutan dengan mengikutsertakan variabel lain seperti harga, lokasi, promosi, lingkungan fisik dan non fisik, citra perusahaan dan sebagainya, melakukan penambahan jumlah responden dan menggunakan metode penelitian yang berbeda untuk mendapatkan hasil yang lebih tepat.

\section{DAFTAR PUSTAKA}

Badan Pusat Statistik. (2016). Pariwisata. Medan. Retrieved from https://sumut.bps.go.id/

Daniel, C. N., \& Berinyuy, L. P. (2010). Using the SERVQUAL Model to assess
Service Quality and Customer Satisfaction. An Empirical Study of Grocery Stores in Umea. Umea School of Business, 1-78. Retrieved from http://umu.divaportal.org/smash/record.jsf?pi $\mathrm{d}=$ diva2:327600

Fornell, C. (1992). Satisfaction Barometer: The Swedish Experience. Journal of Marketing, 56(1), 6-21.

Giese, J. L., \& Cote, J. a. (2002). Defining Consumer

Satisfaction. Academy of Marketing Science Review, 1(3), 272-8. https://doi.org/10.1111/j.13652850.2008.01371.x

Harmen, H., Agustini, F., Harahap, L. M., \& Amanah, D. (2017). Analysis of Factors Influencing the Visitor Satisfaction on Pantai Cermin, Indonesia. IOSR Journal of Business and Management Ver. II, 19(6), 2319-7668. https://doi.org/10.9790/487X1906024753

Jin, N. P., Lee, S., \& Lee, H. (2015). The effect of experience quality on perceived value, satisfaction, image and behavioral intention of water park patrons: New versus repeat visitors. International Journal of Tourism Research, 17(1), 82-95. https://doi.org/10.1002/jtr.196 8

Kim, S.-J. (2011). A Study on the Importance and Satisfaction of the Waterpark Quality Evaluation Factors. Korea Computer Information Academic Journal, 16(3), 
237-249.

Kotler, P., \& Armstrong, G. (2014). Principles of Marketing. (2016). Principles of Marketing. London: Pearson Education.

\& Keller, K. L. (2016a). A Framework For Marketing Management.

(2016b). Marketing Management. Global Edition (Vol. $15 \mathrm{E})$. https://doi.org/10.1080/08911 760903022556

P.Srinivas Rao, P. C. S. (2013). Impact of Service Quality on Customer Satisfaction in Hotel Industry. IOSR Journal of Humanities and Social Science, 18(5), 39-44. https://doi.org/10.1007/s40622 -014-0028-2

Parasuraman, A. (2002). Service quality and productivity: a synergistic perspective. Managing Service Quality: An International Journal, 12(1), 6-9. https://doi.org/10.1108/09604 520210415344

Selvakumar, J. J. (2015). Impact of Service Quality on Customer Satisfaction in Public Sector and Private Sector Banks. Purushartha: A Journal of Management Ethics and Spirituality, 8(1), 1-12.

Stemvelt, R. C. (2004). Perception of Service Quality. Massachusett: Allyn and Bacon.

Tse, D. K., \& Wilton, P. C. (1988). Models of Consumer Satisfaction Formation: An Extension. Journal of Marketing Research, 25(2), 204. https://doi.org/10.2307/31726 52

Wu, H.-C., Li, M.-Y., \& Li, T. (2018). A Study of Experiential Quality, Experiential Value, Experiential Satisfaction, Theme Park Image, and Revisit Intention. Journal of Hospitality \& Tourism Research (Vol. 42). https://doi.org/10.1177/10963 48014563396

Yeong, W. Y., Chang, Z. Y., \& Loh, L. (1997). The Quest for Global Quality: A Manifestation of Total Quality Management by Singapore Airlines. Addison-Wesley. 